\title{
ESTILOS
}

DOI: https://doi.org/10.11606/issn.1981-1624.v24i2p276-290.

\section{Artigo \\ O fenômeno social no entorno da epidemia de zika como potencial complicador à constituição psíquica do bebê}

\author{
Fernanda Fernandes da Silva; Leopoldo Fulgencio
}

\begin{abstract}
Resumo. Este artigo busca analisar a relação entre a epidemia de Zika, ocorrida no Brasil entre 2015 e 2017, e o cenário social fóbico estabelecido entre as gestantes e seus familiares a espera de um bebê. O objetivo é fazer uma exploração teórica, com base numa perspectiva psicanalítica, ou seja, que considera os processos inconscientes na constituição do sujeito psicológico, impulsionado pela sexualidade no cenário edípico, o que implica, nesse cenário da epidemia de Zika, a reorganização das identidades paternas e maternas impregnadas pelo medo de trazer ao mundo um bebê com necessidades especiais ou, ainda, com complicações consideradas incompatíveis com a vida.
\end{abstract}

Palavras-chave: Zika; objeto fóbico; constituição psíquica; microcefalia.

\section{El fenómeno social en el entorno de la epidemia de zika como potencial complicador a la constitución psíquica del bebé}

Resumen. Este artículo busca analizar la relación entre la epidemia de Zika, ocurrida en Brasil entre 2015 y 2017, y el escenario social fóbico establecido entre las gestantes y sus familiares durante la espera de un bebé. El objetivo es hacer una exploración teórica, con base en una perspectiva psicoanalítica, o sea, que considera los procesos inconscientes en la constitución del sujeto psicológico, impulsado por la sexualidad en el escenario edípico, lo que implica, en ese escenario de la epidemia de Zika, la reorganización de las identidades paternas y maternas impregnadas por el miedo de traer al mundo un bebé con necesidades especiales o, aún, con complicaciones consideradas incompatibles con la vida.

Palabras clave: Zika; objeto fóbico; constitución psíquica; microcefalia.

The social phenomenon in the environment of zika's epidemic as a potential complicator to the baby's psychic constitution

1. Doutoranda em Psicologia da Educação e do Desenvolvimento Humano na Universidade de São Paulo,

São Paulo, Brasil. E-mail: psico.fernanda@usp.br

2. Professor Livre-Docente do Instituto de Psicologia da Universidade de São Paulo, São Paulo, Brasil. Email: lfulgencio@usp.br 


\begin{abstract}
This paper aims to analyze the relationship between the Zika epidemic that occured in Brazil from 2015 to 2017 and the phobic social scenario established between pregnant women and their relatives who will receive a baby in the family. The objective is to make a theoretical exploration, based on a psychoanalytical perspective, which considers the unconscious processes in the constitution of the psychological subject, driven by sexuality in the Oedipal scenario and therefore result, in this scenario of Zika virus, the reorganization of the paternal and maternal identities impregnated by the fear to bring to the world a baby with special needs or even with complications that are considered incompatible with life.
\end{abstract}

Keywords: Zika; phobic object; psychic constitution; microcephaly.

\title{
A epidemia de Zika no Brasil e sua presença na vida psíquica
}

No final de 2015 a imprensa começou a noticiar o crescente número de bebês nascidos com microcefalia1. Ainda não se sabia o que estava acontecendo, mas chamava a atenção dos médicos o aumento exponencial de nascimentos com essa malformação na região nordeste do país. Ao se atingir vinte e seis casos confirmados de bebês com diagnóstico de microcefalia em Pernambuco, a secretaria de saúde do estado notificou e solicitou o apoio do Ministério da Saúde para fazer uma investigação - a suspeita era de uma epidemia, mas a causa era desconhecida.

Apesar das evidências, a comunidade internacional demorou a reconhecer a relação do vírus da $\mathrm{Zika}^{2}$ com a ocorrência da microcefalia em bebês. Muitos outros casos surgiram em quase todos os estados do Brasil, gerando muita dúvida e apreensão, especialmente entre as mulheres gestantes e aquelas que pretendiam engravidar. Neste período, surgiram, de um lado, recomendações oficiais sobre os cuidados e prevenções, e de outro, recomendações não oficiais veiculadas pela mídia sugerindo que as mulheres adiassem o momento da gestação. No auge da epidemia, o boletim epidemiológico de $n^{\circ} 31$ (setembro/16) do Ministério da Saúde registrou 14.739 casos prováveis de infecção pelo vírus da Zika em gestantes no Brasil, sendo 6.903 confirmados por critério clínico-epidemiológico ou laboratorial, segundo dados do Sinan-NET ${ }^{3}$ publicados pelo Ministério da Saúde (portalms.saude.gov.br/boletinsepidemiologicos). Eram quase quinze mil gestantes vivendo à espera de bebês marcados pela possibilidade de malformações, atrasos no desenvolvimento e até mesmo a morte.

As malformações congênitas, dentre elas a microcefalia, têm etiologia complexa e multifatorial e podem ocorrer como resultado de processos infecciosos durante a gestação. As pesquisas sobre a epidemia avançaram e foi possível fazer a correlação entre a presença do vírus da Zika na gestante e a ocorrência de microcefalias. O ponto de partida que permitiu chegar a essa correlação foi a detecção de resultados positivos para a presença do vírus da Zika nos exames de duas gestantes, que faziam acompanhamento com a obstetra paraibana, Dra. Adriana Melo, especialista em medicina fetal.

1 Trata-se de uma malformação congênita, em que o cérebro não se desenvolve de maneira adequada. Neste caso, os bebês nascem com perímetro cefálico (PC) menor que o normal, que habitualmente é superior a $32 \mathrm{~cm}$.

2 O vírus Zika é um arbovírus (grande família de vírus), transmitido pela picada do mesmo vetor da dengue, o Aedes aegypti.

3 O Sinan Net (Sistema de Informação de Agravos de Notificação) tem como objetivo coletar, transmitir e disseminar dados gerados rotineiramente pelo Sistema de Vigilância Epidemiológica das três esferas de Governo, por meio de uma rede informatizada, para apoiar o processo de investigação e dar subsídios à análise das informações de vigilância epidemiológica das doenças de notificação compulsória. 
A reunião das evidências foi fruto de um trabalho em conjunto liderado pela Dra. Celina Turchi, pesquisadora da Fiocruz indicada pela revista Nature ao prêmio de personalidade do ano de 2016 na categoria ciência, como reconhecimento de seu trabalho. (A. Costa, 2016)

Nesta fase, tanto a comunidade médica quanto as famílias já tinham conhecimento sobre os possíveis riscos para o desenvolvimento desses bebês. Antes dessa confirmação, porém, o medo e as dúvidas vinham ganhando força com as inúmeras reportagens e depoimentos das mães que haviam parido bebês com complicações congênitas. Sabe-se que a contaminação da mãe no período da gestação é fator de risco, mas não de certeza sobre a existência de alguma complicação neurológica para o feto (Zorzetto, 2016). Como em outras infecções congênitas, o desenvolvimento dessas anomalias depende de diferentes fatores que podem estar relacionados a outras causas.

Com o expressivo número de gestantes em contato com o vírus Zika e, ao mesmo tempo, a incerteza quanto à saúde física e psíquica destes bebês, cria-se um cenário obscuro do ponto de vista emocional, no que se refere às expectativas destes pais frente aos exames pré-natal. Não resta dúvida sobre a importância de ações preventivas, assim como da necessidade de divulgação de informações acerca de todos os cuidados e protocolos construídos para a detecção da infecção e acompanhamento destas gestantes. No entanto, a expectativa gerada em torno de uma provável detecção de microcefalia confere um roteiro sombrio ao período de preparação para a chegada do bebê.

Nunes e Pimenta (2016) fazem uma crítica contundente ao viés político sobre o conceito de saúde global e a aparente neutralidade que envolve todas as medidas de prevenção e tratamento para essa epidemia ocorrida no Brasil. Dos apontamentos levantados, destaca-se a crítica referente a um dos aspectos que eles consideram dentre os fatores negligenciados:

A experiência de 'estar doente' ou 'ser saudável' não é uniforme, mas sempre contextual, dependente de variáveis como a situação social e econômica, o gênero, a raça, a orientação afetiva e sexual, a idade ou a existência de incapacidades. (Nunes \& Pimenta, 2016 p. 27)

Tais variáveis têm poder de impactar o curso de vida destas pessoas, não apenas porque afetam a resposta à doença, mas também porque perpetuam uma condição de vulnerabilidade espelhada pelo Estado e pela mídia, no contexto desta epidemia, especialmente entre mulheres e gestantes com menos acesso aos serviços básicos de saneamento e informações.

De um lado estão as mães que obtiveram confirmação de malformação ainda na gestação. Elas estavam inseridas num contexto social e midiático que divulgava uma avalanche de informações sobre as possíveis limitações da criança com microcefalia. Neste momento, o risco e as limitações para a criança decorrentes da contaminação ganham destaque na imprensa - essa família, então, precisa conviver com a metabolização de uma informação no âmbito privado de suas vidas que, no entanto, é tema de discussão e especulação por toda a sociedade. Cabe aqui uma primeira pergunta: o fenômeno social em torno da epidemia poderia "contaminar" as expectativas parentais?

De outro lado temos as mães que, apesar da contaminação pelo vírus, tiveram bebês com um perímetro cefálico dentro de parâmetros normais. Estes bebês, porém, continuariam a conviver com o risco da presença de outras complicações ao longo de seu desenvolvimento. Assim, essas crianças foram inseridas em programas de acompanhamento e investigação, e isto significa que o fantasma da deficiência não fora totalmente afastado, pois ele ronda essa criança que deverá frequentar as mesmas salas de espera dos bebês com comprometimento confirmado. Cabe aqui, então, uma segunda pergunta: é possível que esse cenário fóbico 
construído em torno da chegada e do desenvolvimento do bebê exerça alguma influência nas bases da constituição psíquica destes indivíduos?

Afastamo-nos de um determinismo linear de causa e efeito e optamos por recorrer ao conceito freudiano de séries complementares (Freud, 1916) que propõe que os fatores constitucionais e a influência do meio são reciprocamente modificados. Recorremos também ao moderno conceito de psiquiatria perinatal, constantemente evocado pelo psicanalista francês Bernard Golse (2012) para compreender o que ele denomina de "patologias da interação", ou seja, entende-se aqui que qualquer uma das partes da díade mãe-bebê teria potencial para adoecer a outra. Essa leitura do conflito substitui o pensamento simplista que preconizava uma culpabilidade à mãe. Nessa proposta, a intervenção visará restabelecer a capacidade da díade de identificação, sustentação e investimento. (Viodé-Bénony, 2012).

Observamos que o diagnóstico de contaminação pelo vírus da Zika durante a gestação não é certeza de microcefalia e que muitos são os bebês que, mesmo com diagnóstico positivo para a presença do vírus na mãe, nascem aparentemente saudáveis. Para esses casos, assim como para os nascidos com a microcefalia, o Ministério da Saúde publicou o "Protocolo de Vigilância e Resposta à Ocorrência de Microcefalia e/ou Alterações do Sistema Nervoso Central (Snc)" que orienta para a identificação dos casos suspeitos, fluxo de notificação, investigação laboratorial e medidas de prevenção e controle.

A seguir, destaca-se o que prevê as orientações gerais do referido protocolo para os casos em que não se confirmou a microcefalia logo após o nascimento:

\begin{abstract}
Apesar de reconhecer a inexistência de sinal patognomônico que permita caracterizar com precisão a infecção, por exames de imagem, o Ministério da Saúde informa que para a finalidade exclusivamente de vigilância em saúde, visando a triagem dos casos para melhor investigação das causas, serão considerados sugestivos de infecção congênita todos os casos que apresentarem alterações do sistema nervoso central, definidas pela presença de pelo menos um sinal maior (exemplo: alterações ventriculares ou calcificações, principalmente as subcorticais, etc.) ou dois sinais menores (alterações de fossa posterior), independentemente da medida do perímetro cefálico, circunferência craniana ou resultados laboratoriais. Todos os casos que se enquadrarem nessa condição, serão considerados "confirmados por critério clínico radiológico" e poderão ser submetidos a investigações complementares para que, no futuro, seja possível discriminá-los segundo a etiologia e, eventualmente, podendo ser descartados caso seja comprovada a origem não infecciosa dessa alteração do SNC identificada. (2016, pp. 23-24)
\end{abstract}

A proposta insere um grande número de bebês nesse programa de investigação e supõe que muitos serão descartados por não apresentarem alterações significativas durante seu desenvolvimento. A decisão é profilática, pois o intuito é evitar que bebês com alterações deixem de receber a assistência por falta de diagnóstico. O grande complicador que fora negligenciado neste processo é o fator emocional da díade mãe-bebê e de todo o contexto familiar. Qual é o impacto emocional para os pais que terão que lidar com o risco de involução ou aparecimento de problemas na primeira infância dessas crianças? Ao mesmo tempo, questionamos que tipo de espelhamento os pais e a sociedade oferecem a esses bebês.

O diagnóstico de microcefalia em todo o mundo tem uma alta porcentagem de erro. É comum constatarem ao longo do desenvolvimento da criança que o perímetro cefálico diminuído tem fator genético e não patológico, conforme aponta o epidemiologista Cesar Victora: "A grande maioria das crianças classificadas com microcefalia em qualquer país que segue a recomendação da OMS [ou seja, aquelas que estão dois desvios-padrão abaixo da média] será normal com a cabeça pequena" (Zorzetto, 2016, p. 17). A decisão do Ministério da Saúde de considerar apenas "dois sinais menores" para a inserção no programa aumenta a 
possibilidade de erro no diagnóstico e, junto com isso, cresce o número de bebês que precisarão lidar, desde o início de suas vidas, com o temor dos pais frente à possibilidade de confirmação de uma deficiência.

Estas crianças e suas mães foram inseridas em programas de acompanhamento específicos através da atenção básica, maternidade/hospitais, laboratórios e ambulatórios de reabilitação pelo SUS (Sistema Único de Saúde) até que completem cinco anos, conforme prevê o protocolo do Ministério da Saúde:

O objetivo é estabelecer normas internacionais de crescimento para medir e melhorar o atendimento clínico para as mães e as crianças e comparar os resultados entre as populações, além de ampliar os Padrões de Crescimento Infantil da OMS para o período fetal e neonatal e dar ferramentas para a continuidade dos cuidados desde a concepção até 5 anos de idade. (2016, p. 24)

Tal recomendação parece se justificar pelo fato de que não houve tempo para observar essas crianças ao longo de muitos anos. Suspeitava-se que poderiam aparecer outras complicações durante esses primeiros anos do desenvolvimento e, infelizmente, essa suspeita vem se confirmando; pesquisadores brasileiros observaram uma incidência de problemas oculares em crianças sem microcefalia (Ventura, Maia, Dias, Ventura, \& Jr, 2016). A Dra. Camila Ventura, responsável por essa pesquisa, fez a seguinte recomendação em reportagem da jornalista Camila Costa (2016):

É preciso levar em consideração o quadro neurológico da criança, não só o tamanho da cabeça. Em qualquer suspeita de que existam lesões no cérebro tem que se levantar a Síndrome Congênita da Zika, dentro do guarda-chuva de possibilidades. (http://www.bbc.com/portuguese/brasil-36465913)

A constatação de que bebês sem microcefalia começaram a apresentar outros tipos de complicações neurológicas vai ao encontro da crítica inicial do Ministério da Saúde, que decidiu ampliar os critérios de inserção destes bebês, assumindo assim, o risco de incluir crianças saudáveis. Porém, cientes da necessidade de inserção destas crianças nos programas de controle do desenvolvimento, o questionamento que surge é como prevenir os efeitos nocivos de um cenário social que vem trazendo a público, de tempos em tempos, novas complicações possíveis para essa Síndrome Congênita da Zika?

As gestantes e as mulheres que pretendiam engravidar ao longo do ano de 2016 foram confrontadas com notícias, dúvidas, boatos e algumas constatações em torno das previsões sobre a epidemia da Zika. O ineditismo da epidemia motivou alertas que inflacionaram o temor da população. Naquele ano, o Brasil sediaria os Jogos Olímpicos, porém, mais de cem cientistas reivindicaram em uma carta aberta à Organização Mundial da Saúde o adiamento ou a transferência dos Jogos para outra nação (Puff, 2016). Entretanto, o pedido não foi atendido e, após os Jogos, a OMS publicou uma nota afirmando que não houve relato de um único turista contaminado pelo vírus da Zika no Brasil. Em maio de 2017, exatamente um ano depois dos Jogos Olímpicos, o Ministério da Saúde declarou o fim da emergência nacional de Zika que se estendeu por dezoito meses, alegando que houve uma redução de $95 \%$ dos casos. (Brasil, 2017a)

A epidemia de Zika durou entre novembro de 2015 a maio de 2017 e acumulou um total de 13.719 notificações referentes aos bebês nascidos com suspeita de alterações no crescimento e desenvolvimento, possivelmente relacionados à infecção pelo vírus da Zika (Brasil, 2017b). Todas essas famílias tiveram que encontrar um modo de lidar com o medo, a certeza ou o alívio frente ao risco de confirmação da microcefalia em seus bebês. Desse total, 
2.722 bebês $(19,8 \%)$ tiveram o diagnóstico de microcefalia confirmado e registrado pelo Ministério da Saúde. (Brasil, 2017b) Restam, então, mais de 10 mil bebês que tiveram seu nascimento e desenvolvimento inicial marcados pelo medo da microcefalia, sem, no entanto, uma alteração real que justifique ou personifique todo o pavor gerado em seu entorno. Haveria algum potencial danoso neste contexto social e familiar para a constituição psíquica desses bebês? Qual o destino desses afetos e, mais especificamente, do medo nas representações parentais?

O termo fobia é utilizado "para designar o pavor de um sujeito em relação a um objeto, um ser vivo ou uma situação" (Roudinesco \& Plon, 1998, p. 243). Em psicanálise, a fobia é um sintoma que pode estar presente em todas as estruturas clínicas (Roudinesco \& Plon, 1998). Entretanto, é central na histeria de angústia, na qual a libido não é convertida em sintoma físico (tal como na histeria de conversão), mas sim liberada sob a forma de angústia (Freud, 1909). Uma característica essencial na formação de um sintoma fóbico consiste no trabalho psíquico empreendido no sentido de ligar de novo, psiquicamente, a angústia que ficou livre (Laplanche \& Pontalis, 1986).

O paralelo entre o contexto fóbico da epidemia de Zika inundado por angústias impulsionadas pelos diferentes comprometimentos que foram surgindo ao longo do primeiro ano de vida destes bebês e, mais precisamente, pelo fenômeno midiático, permite-nos levantar a hipótese de que a sociedade deve a esses pais uma explicação no sentido de ajudá-los a religar o "afeto às representações".

Como explicar o fato de que mais de cem cientistas pediram o adiamento de um evento sob a justificativa de proteger a população de um terrível risco que se mostrou absolutamente contornável com a aplicação de repelente? Parece haver uma ponta solta entre essa carga afetiva e seus representantes ideacionais. Não há uma explicação que reorganize o pavor gerado neste período, e nem sequer podemos ter acesso ao número de crianças nascidas com microcefalia antes da epidemia para compará-lo aos números atuais, porque estes casos não eram de notificação obrigatória até então. Tem-se em paralelo ao fenômeno epidêmico, do ponto de vista emocional, um fenômeno psicossocial com características capazes de se desligar do real e aumentar em muito seu potencial patogênico.

\section{O aspecto fóbico como elemento constitutivo da psique do bebê}

A proposta de reunir contribuições de diferentes escolas, a saber, winnicottiana e lacaniana não visa aproximar ou integrar sistemas teóricos díspares, mas sim apreender de cada contribuição a descrição dos fenômenos em jogo.

O bebê, com sua fragilidade inicial, necessita de sustentação e cuidados oferecidos por um Outro-primordial, "nomear a mãe de Outro-primordial é insistir na importância desse lugar a que a função dá suporte" (Faria, 2016, p. 39). A autora interpreta que Lacan (1957), ao chamar a mãe de Outro-primordial tinha como objetivo articular o lugar à função e destacar a importância do suporte concreto que permite à criança ser inserida num circuito interpretativo.

Antes de a mãe ser capaz, entretanto, de decifrar os códigos do bebê, é necessário que ela os antecipe através de uma suposição construída a partir da interpretação que fará das manifestações do corpo deste bebê, ou seja, a interpretação das "necessidades" do bebê constitui uma construção materna que poderá ou não, futuramente, ser apropriada por ele. 
Essa construção implica um circuito interpretativo que envolve a díade: "O choro não apenas é interpretado pela mãe como tendo um sentido - fome, frio, sono - mas um sentido que sugere um endereçamento, demanda: se o bebê chora é porque demanda algo dela" (Faria, 2016, p. 37).

A psicanalista Laznik postula o olhar materno como suporte do processo que deve viabilizar a integração da imagem corporal do bebê. (2004) Apoiada no estádio do espelho proposto por Lacan (1949), ela confere um lugar central ao "olhar" na clínica dos fenômenos de interação mãe-bebê. $\mathrm{O}$ ver e o olhar são diferenciados pela referida autora à medida que o segundo comporta esse aspecto de "suposição" das manifestações do bebê "o olhar justamente no que ele se opõe à visão, avista não o que está aí, mas um vir a ser, um advir - o que nos leva à noção de ilusão antecipadora" (Laznik, 2004, p. 55) O problema é quando essa "ilusão antecipadora" está impregnada de fantasmas e descrições minuciosas veiculadas pela mídia e pelos profissionais acerca das possíveis limitações desse bebê: dificuldade de mamar, movimentar-se, dormir etc.

Cabe aqui um parêntese. Essa suposição, ou ilusão antecipadora, necessita de um apoio no corpo real do bebê, ou ainda, em seu gesto espontâneo, do contrário, pode tornar-se invasivo e favorecer a construção do que Winnicott propõe como falso-self caso a mãe tenha dificuldades em oferecer esses enunciados ao seu bebê:

\footnotetext{
A mãe suficientemente boa alimenta a onipotência do lactente e até certo ponto vê sentido nisso. E o faz repetidamente. Um self verdadeiro começa a ter vida, através da força dada ao fraco ego do lactente pela complementação pela mãe das expressões de onipotência do lactente. A mãe que não é suficientemente boa [...] ao invés, ela o substitui por seu próprio gesto, que deve ser validado pela submissão do lactente. Essa submissão por parte do lactente é o estágio inicial do falso self, e resulta da inabilidade da mãe de sentir as necessidades do lactente. (Winnicott, 1960, p. 133)
}

Retomando a discussão sobre o olhar proposta por Laznik, Crespin (2004) faz um paralelo entre a noção de grande Outro desenvolvida por Lacan em seu trabalho Estádio do Espelho (1949), no qual este conceito é introduzido sob a forma de um espelho plano que reflete uma imagem especular, dele mesmo, que será responsável pela formação do eu à medida que faz uma antecipação visual à imaturidade motora; e a publicação de Winnicott, segundo ele influenciada pela publicação de Lacan, da obra $O$ papel do espelho da mãe e da família no desenvolvimento da criança (1967), no qual Winnicott propõe que a mãe reflita justamente, ele mesmo (o bebê), porém, adverte que uma "mãe deprimida" ou "psiquicamente ausente" na relação devolveria ao bebê, sob os seus cuidados, uma imagem "dele mesmo" que pode ser problemática.

Começamos a nos aproximar do tema que orienta nossa discussão à medida que colocamos em cena um contexto que pode ter atravessado as expectativas maternas e interferido no olhar que esta consegue dirigir ao seu bebê: a epidemia de Zika e seus efeitos no imaginário dessas mães.

Selecionamos um exemplo publicado por Laznik que retrata bem a problemática em questão. Ela relata o caso de uma mulher que, estando no quinto mês de gestação, observa uma alteração na ultrassonografia de rotina - havia alterações em certos percentuais de medida do feto. Sendo médica, a gestante foi capaz de interpretar que a suspeita de seu obstetra era em torno da trissomia (síndrome de Down). Quinze dias depois o risco foi descartado, porém, o pesadelo vivido deixou marcas. Reproduziremos aqui o texto redigido pela gestante acerca de seus sentimentos frente àquela informação: 


\begin{abstract}
Abrigo um ser monstruoso e disforme, sou defeituosa. Barriga indecente. Sentimento de vergonha, após um orgulho tão grande. Cada movimento do bebê me parece anormal: faz bolhas com sua boca, tem movimentos anárquicos de braços e pernas. Tornou-se o trissômico e assim nomeio cada vez que penso nele, ou seja, quase o tempo todo. A partir do momento onde apenas uma dúvida se instaurou, iniciei instantaneamente meu luto como se fosse uma coisa certa, sem poder refletir. A imagem do lindo menininho, seu rosto, se transformou na figura do mongólico horroroso. Vontade de chorar a cada vez que penso nele, ou a cada vez que perguntam a seu respeito. Antes eu olhava seu perfil na ultrassonografia todos os dias com emoção e ternura. Depois, como seu nariz foi considerado muito curto, nunca mais olhei essa imagem. (Laznik, 2004, p. 41)
\end{abstract}

A hipótese da autora é que a transformação na imagem inconsciente do bebê engendrada pela mãe será capaz de refletir, neste caso negativamente, sobre a imagem do corpo do bebê; seria essa imagem a responsável pela vivência da unidade do corpo. Para a autora, o reasseguramento da equipe médica, que oferece a essa mãe suporte e condições de reorganização para as representações e afetos em torno do equívoco, seria suficiente para ajudá-la a retornar ao processo de investimento no bebê que está gestando.

No caso das mães que integram os programas de cuidados para os nascidos com alterações relacionadas ao vírus da Zika não há trégua - mesmo quando descartado o risco de microcefalia no nascimento, elas continuam o acompanhamento à espera de outras alterações possíveis que vem sendo anunciadas, paulatinamente, conforme essas crianças crescem.

Parece significativo o fato de que, considerando os aspectos inconscientes em jogo, os pais, em vez de assistirem jubilosamente o desenvolvimento de seu bebê, identificarem-se com a equipe de saúde na investigação por algo que desvia dos marcos do desenvolvimento. Nesta lógica, mesmo não progredir, ainda sim, parece razoável, a expectativa passa a ser uma torcida por exames neurológicos sem alterações. A questão refere-se a essa retração nas expectativas parentais frente ao desenvolvimento da criança. Como projetar essa antecipação jubilosa quando as expectativas são atravessadas por riscos que ferem o narcisismo destes pais?

Para a psicanalista Piera Aulagnier (1975), o desejo parental compõe o pré-investimento psíquico (partindo dos pais em direção ao que ela chama de corpo ainda ausente do bebê), ou seja, todo esse cenário construído no entorno do bebê será a "matéria-prima" fundamental para a construção psíquica da criança que está por vir. Neste caso, a criança em questão está "sorologicamente" marcada pela possibilidade de destruir o projeto narcísico destes pais. Entretanto, ter nascido com um perímetro cefálico dentro dos padrões de normalidade garante alguns pilares de sustentação para esse edifício de risco iminente.

Entre a equipe de saúde e a criança existe uma mãe que fornecerá, para além dos exames de imagem e laboratoriais de seu bebê, uma leitura de seu desenvolvimento que poderá ser acolhida dentro de uma singularidade ou simplesmente pautada nos marcos desenvolvimentais pré-estabelecidos. Outro ponto seria o quanto essa "leitura materna" pode ser ajustada para ver a partir de um saber médico, ou ainda, exageradamente dependente das lentes deste. A interpretação das manifestações da criança será transmitida à equipe de saúde por essa porta-voz que encarna a função materna:

[...] porta-voz no sentido literal do termo, pois é a esta voz que o infans deve, desde seu nascimento, o fato de ter sido incluído num discurso que, sucessivamente, comenta, prediz, acalenta o conjunto de suas manifestações, mas porta voz, também no sentido de delegado, de representante de uma ordem exterior cujo discurso enuncia ao infans suas leis e exigências. (Aulagnier, 1975, p. 106) 
No cumprimento desta função de "delegado", a voz materna faz o caminho inverso e enuncia à criança as leis e exigências do mundo exterior. Quais são as exigências para uma criança que vem se safando do tão temido diagnóstico de microcefalia ou de qualquer outra complicação possível neste cenário desconhecido?

A propósito, sobre o temor, parece ser uma emoção muito presente no roteiro destes pais. Para Dolto (2013), todo medo contém em seu avesso um desejo, e conferir um índice libidinal ao objeto fóbico pode representar uma defesa importante [e perigosa] para que seja possível garantir alguma integridade psíquica.

Se eu fosse esse objeto que me dá medo, se eu me identificasse com ele, eu teria o poder absoluto que uma outra pessoa tinha sobre mim, em certa época de minha vida; ora, dependente desse objeto que me dá medo, eu já não sou eu. Logo sou des-realizado. (p. 185)

Identificar-se precocemente com a condição limitante (encarnação do objeto fóbico), mesmo antes da confirmação de um diagnóstico, pode ser um recurso da criança para proteger a si e aos pais da 'decepção'. A constituição psíquica do sujeito se dá prioritariamente na relação parental; os pais/cuidadores, por sua vez, estão inseridos num dado meio social.

Para Aulagnier (1975), um mínimo de conformidade dos pais com o que se espera da maternidade ou paternidade na sociedade em que estes vivem é um importante parâmetro de saúde na constituição psíquica da criança. Entretanto, considerando a inversão nas expectativas parentais, em que medida essa indefinição pode refletir um atravessamento no jogo de desejos parentais frente à criança, assim como uma ambiguidade nas referências identificatórias fundamentais para constituição psíquica desta?

A transmissão psíquica entre as gerações representa uma articulação entre o complexo de Édipo e o superego dos pais com o psiquismo em construção da criança. Para Azevedo, FéresCarneiro e Brandão (2018), é importante destacar o papel do pai mais articulado ao desejo e menos à função de interdição. Os autores citam a predominância do significante Nome-do-pai sobre a função de genitor. Porém, como se dá a impregnação da articulação entre Lei e desejo num contexto fóbico?

Dolto (2013) enfatiza o potencial patogênico para o futuro adulto da construção de uma fobia no período anterior ao Édipo, pois no auge do período edípico, o objeto fóbico se tornaria o centro do conflito como o "elemento capital da angústia":

Um ser fóbico desde a primeira infância já encontrou benefícios na fobia: são contrapartidas a uma retaliação predominantemente sádica, ou, ao contrário, de compaixão, da parte das pessoas à sua volta; todos girando em volta da criança, utilizando sua fobia para fixá-la nela cada vez mais. (p. 186)

Promover um amálgama entre a criança e os fantasmas parental e social em torno de uma limitação, dependência ou malformação é bem diferente do que propõe Winnicott (1975) com a ideia de que o espelhamento possa devolver à criança "ela mesma". Ela mesma não é, de modo algum, sinônima de uma síndrome congênita da Zika, nome esse capaz de comportar em seu "guarda-chuva de possibilidades" o temor frente ao risco de desintegração que ronda todo ser humano em seu estado inicial.

Fulgencio (2016) interpreta que o risco de um colapso na situação inicial pode ser vivido como consequência de uma "catástrofe de aniquilação do self central pela falha ou intrusão ambiental". (p. 221) Esse tipo de vivência inicial pode desembocar numa dificuldade em "ser" 
a partir de si mesmo e principalmente "viver de modo que a vida valha a pena ser vivida". (p. 221)

\section{Cataria Maria - o caso número 1 da epidemia de Zika}

A epidemia de Zika trouxe ao cenário social e familiar desafios e reflexões singulares. Selecionamos uma vinheta, veiculada pela mídia, sobre o caso de uma criança, para somar aos argumentos sobre a necessidade de sustentação ambiental e investimento libidinal neste contexto. Trata-se do caso da criança Cataria Maria, que ficou conhecida como sendo o caso número 1 da epidemia do vírus Zika. As crianças Catarina Maria e João Guilherme foram o ponto de partida para as pesquisas que tornaram possível a correlação entre a infecção da Zika e os bebês nascidos com microcefalia. João Guilherme faleceu poucas horas após o nascimento, já Catarina Maria completou um ano de vida em fevereiro de 2017. Apesar do diagnóstico de microcefalia, ela cresce e se desenvolve com parâmetros muito próximos ao normal. A mãe relatou em reportagem - dirigida pelos jornalistas Giuliana Bergamo e Hugo Soares - ter ouvido de sua médica que, se sua filha sobrevivesse, ficaria em estado vegetativo. A mãe da criança, a fisioterapeuta Maria da Conceição Matias, embora tivesse experiência no acompanhamento de crianças com necessidades especiais, encontrou-se sem parâmetros para conduzir o tratamento da filha, uma vez que se tratava do primeiro caso confirmado.

A iniciativa dessa mãe foi, no entanto, apostar num esquema de estimulação diária com sua bebê, e o resultado disso foi um desenvolvimento atípico e muito além do esperado para o grau de comprometimento neurológico da criança. Na mesma reportagem, a Dra. Adriana Melo, obstetra responsável pelo acompanhamento dos dois primeiros casos confirmados, concluiu que o desenvolvimento de Catarina Maria é um indicador de que a recomendação do SUS de duas sessões semanais de fisioterapia, prevista como protocolo, seriam insuficientes.

O relato desse caso foi necessário para levantar a seguinte questão: seria apenas o número de sessões de fisioterapia o ponto central para a grande diferença entre as crianças atendidas pelo programa do SUS e o que recebeu Cataria Maria? Além do número maior de sessões de fisioterapia, essa criança recebeu de sua mãe um investimento que dificilmente poderia receber de qualquer outro profissional na mesma proporção. Na entrevista, a mãe da criança relata o quão importante foi o apoio que recebeu de seu esposo e de sua mãe desde o início. Além disso, ainda que a medicina não tivesse recomendações precisas a lhe oferecer, a equipe de epidemiologistas e, especialmente a Dra. Adriana Melo, mostraram-se solidárias e gratas por sua colaboração com as pesquisas.

Entendemos que o apoio que recebeu a mãe de Catarina tem um peso significativo na maneira como pôde construir as bases para o exercício de sua parentalidade. A parentalidade é entendida como uma construção subjetiva que tem, na infância de cada um dos pais, os elementos fundamentais para seu desenvolvimento (Zornig, 2010), sem desconsiderar, o papel ativo do bebê, com suas competências interativas (Houzel, 2004), capazes de promover ressignificação às feridas narcísicas dos pais. (Freud, 1914)

O protagonismo dessa mãe e a sensibilidade da médica, que acolheu a queixa intuitiva dessa gestante a respeito da febre decorrente da contaminação pelo vírus da Zika que tivera no início da gestação, foram os pontos de partida para o desfecho da investigação que culminou na correlação entre o vírus Zika e a incidência de microcefalia nos bebês. O apoio dos 
envolvidos que puderam testemunhar a potência desta mãe pode ter funcionado como um diferencial na capacidade da mesma em investir e cuidar de sua filha.

O elemento fóbico contido nas reportagens e na incerteza presente no discurso das autoridades médicas, característico de um período inicial de pesquisas, parece não ter influenciado negativamente a capacidade de investimento recíproco dessa família. Ao que parece, o fator sustentação esteve presente no contexto desta criança. Isso pode ter favorecido o "olhar" dessa mãe para essa criança que é, para além da síndrome, uma criança. Laznik (2004) propõe que a modificação no olhar materno seja viabilizada pelo próprio médico:

A óptica parental pode ser instaurada, ou mesmo modificada, pelo olhar que o próprio médico tem sobre o bebê. Isto supõe um certo número de condições como estas que permitam ao médico se deixar surpreender pelo 'reizinho' que há no bebê, e aos pais de vir a se identificar com esse 'olhar' do médico. (p. 47)

Promover condições para que esses pais possam, em seu discurso, continuar o investimento no bebê em detrimento da síndrome, parece ser um caminho possível para a constituição tanto da parentalidade quanto da psique do bebê. Insistir e permanecer no discurso sobre o que é e o que esperar da criança com microcefalia é fixar-se no objeto fóbico. Não se trata de ignorar, de modo algum, as possibilidades de comprometimento da criança em acompanhamento, mas de abrir espaço no imaginário parental para as potencialidades dessa criança.

\section{Considerações gerais sobre o problema}

A epidemia de Zika ocorrida no Brasil entre 2015 e 2017 e a contaminação de gestantes trouxe à tona um problema concernente tanto à saúde física quanto psíquica do bebê e dos pais inseridos nesta problemática. Esse tema foi amplamente discutido no Congresso Brasileiro de Psicologia do Desenvolvimento (2017). No entanto, observamos neste contexto a predominância dos trabalhos em psicologia focados e delimitados à tarefa de como divulgar e disseminar o conhecimento acerca das complicações orgânicas que envolvem a síndrome congênita da Zika. O sofrimento e apreensão experimentados pelos pais durante o pré-natal e após o nascimento de seus bebês parece ter sido subestimado. Assim, pouca atenção tem sido dada ao estado psíquico vivido e à pergunta sobre o efeito deste no desenvolvimento psíquico do bebê. Desta maneira, tem-se a impressão de que os profissionais de saúde estão míopes a este aspecto do problema.

O potencial patogênico insuflado pelo fenômeno social e o consequente risco para o desenvolvimento psíquico do bebê parece estar sendo negligenciado. Quais elementos, do ponto de vista emocional, compõem este ambiente que receberá uma criança cuja saúde é incerta? O que pais e sociedade esperam dessas crianças? Estes pais estão lidando com o risco real de má-formação em seu bebê desde a gestação. Após o nascimento, porém, essa preocupação não cessa, e o discurso médico vigente prevê a possibilidade de complicações ainda desconhecidas surgirem ao longo do desenvolvimento da criança.

Entendemos que, tão grave quanto negligenciar um diagnóstico e deixar de incluir a criança num programa de estimulação precoce, que poderia minimizar os problemas em seu desenvolvimento é incluí-la de modo equivocado em um programa de saúde que possa enviesar sua constituição psíquica, assim como a construção da parentalidade desses genitores. Aqui, fazemos referência especificamente ao contingente de mais de dez mil 
crianças que, apesar de terem nascido sem microcefalia, foram diagnosticadas como portadoras da síndrome congênita da Zika em função da contaminação de suas mães durante a gestação. Quais são as limitações decorrentes dessa síndrome? Não se sabe ainda, mas a proposta é justamente incluir todas essas crianças no mesmo programa e acompanhá-las até que completem cinco anos, pois desta maneira será possível identificar as complicações associadas à contaminação materna.

Tal estratégia tem como base a construção de um repertório para fins de saúde pública absolutamente compreensível em seus objetivos. No entanto, do ponto de vista inconsciente, haveria alguma consequência para essa criança que foi inserida num programa que visa encontrar problemas em seu desenvolvimento? É justamente a possibilidade constante de detecção de problemas que pode se configurar como potencial fóbico para os pais. A inclusão destas crianças em um grupo de risco para o desenvolvimento é uma estratégia que compõe uma amostra fundamental para construção de protocolos preventivos e terapêuticos para a população brasileira. Entretanto, há que se considerar a pressão emocional destes pais na condução das investigações e tratamentos de seus filhos.

É controverso pensar em um cuidado que preserva o desenvolvimento neurológico a despeito do complexo processo de constituição psíquica que se opera pelo espelhamento do olhar parental - olhar esse que foi bombardeado por informações que acabam por favorecer a projeção, no corpo em desenvolvimento da criança, de um objeto fóbico. É como se a cada exame ou avaliação da criança, o projeto narcísico destes pais fossem colocados em risco, de tal maneira que o desinvestimento pode tornar-se um processo defensivo contra o sofrimento.

Com relação à criança, é preciso considerar tudo o que ela poderá absorver desta vivência, os diálogos sobre sua saúde ou doença entre as mães, as cenas e os odores hospitalares, a manipulação de seus corpos pelos diferentes terapeutas, o cansaço com o translado até os ambulatórios, etc. Existe a possibilidade, por exemplo, de o diagnóstico de microcefalia acontecer posteriormente ao nascimento, ao longo do tratamento (Van der Linden et al., 2016). Nestes casos, é preciso considerar o impacto desta informação, não somente para a família da criança diagnosticada, mas para os demais familiares que compartilham essas salas de espera.

Se para os pais o desinvestimento pode ser uma saída defensiva, à criança pode restar a possibilidade de se identificar com esse tal objeto fóbico (limitações decorrentes da doença). Assim, ainda que ela tenha se safado da microcefalia, essa espera persistente por limitações desconhecidas que vão sendo reunidas sob o diagnóstico de SCVZ (Síndrome congênita do vírus da Zika) pode dar sentido a toda e qualquer dificuldade encontrada no percurso de crescimento desta criança, senão pelos médicos, talvez pelo imaginário desses pais que ficam desamparados do ponto de vista emocional frente ao temor provocado pelo diagnóstico. Se para Aulagnier (1975), o pré-investimento e a antecipação promovida pelos pais em relação ao bebê compõem a matéria-prima para a constituição psíquica, é importante incluir nessa pauta o papel da saúde mental dos pais.

Temos aqui uma pequena descrição do que poderia compor o que se denomina objeto fóbico no entorno de pais e filhos inseridos no programa de acompanhamento pré e pós-natal, a partir da contaminação materna pelo vírus da Zika.

A dúvida quanto à saúde e a integridade do bebê que está sendo gerado pode fragilizar de modo significativo as possibilidades desses pais de acolher um sujeito singular, bem como de criar um cenário de expectativa jubilosa que antecipe e, assim, crie condições saudáveis para o desenvolvimento. 
Como sustentar a ilusão antecipatória de sujeito psíquico, que venha a se constituir como sujeito desejante, quando o que se tem priorizado é a sobrevivência do organismo dos bebês e a eficiência técnica dos pais, comparados a puericulturistas? (Iaconelli, 2015, p. 145)

Em contrapartida, a sustentação ambiental poderia garantir à mãe as condições necessárias para que possa entrar em um estado de sensibilidade denominado por Winnicott como "preocupação materna primária" (Winnicott, 1958), que permitirá a ela identificar-se com as necessidades do bebê, movimento fundamental para o nascimento saudável da vida psíquica.

Para além de uma psicoterapia que, sabemos ser inacessível para a totalidade dessa população, pensamos na importância da modificação do discurso frente a essa criança e especialmente em relação ao seu futuro. Outro ponto fundamental diz respeito à conscientização dos profissionais sobre a necessidade de acolhimento das especulações fantasmáticas dos pais que poderiam encontrar na palavra um destino preferível ao corpo da criança.

A retração na expectativa parental frente à criança, neste contexto, poderia ser minimizada por profissionais de saúde que estejam comprometidos com um olhar e um discurso que valorize a singularidade desta criança, de modo a favorecer nos pais a percepção de 'vossa majestade o bebê' em detrimento de uma contaminação deste olhar que, ao invés de destinar uma espera jubilosa pelos primeiros passos de seu filho, promova uma torcida por um centímetro a mais na medição do perímetro cefálico que será feito periodicamente. Não há como falar em promoção de saúde para o desenvolvimento infantil sem oferecer condições de sustentação emocional para esses pais.

Assim como se desconhece as limitações provocadas pela Síndrome Congênita da Zika, ignora-se também o destino psíquico dessas informações que atravessam a construção da parentalidade e a constituição psíquica da criança. A possibilidade dos pais de colocar em palavras esses fantasmas, assim como, de receber do profissional um reasseguramento frente à legitimidade do direito de expressarem ambivalência, pode ser um primeiro passo no sentido de colocar luz a esse fenômeno de âmbito emocional que se processa em paralelo aos cuidados oferecidos em função das complicações que possam acometer o corpo em desenvolvimento da criança.

Há uma retroalimentação narcísica no processo de construção parental que se dá em paralelo a constituição psíquica do bebê, neste contexto, a sexualidade dos pais (Freud, 2014), as competências interativas do bebê (Houzel, 2004), e o contexto social cultural são os elementos que compõem o cenário de possibilidades para pais e filhos. $\mathrm{O}$ atravessamento, no entanto, promovido pela inflação social no entorno da epidemia da Zika, pode ter favorecido um "contexto de reprodução de vulnerabilidades e de formas de violência estrutural" (Nunes \& Pimenta, 2016, p. 41) ao negligenciar o papel da construção subjetiva como elemento fundamental de um desenvolvimento físico saudável.

\section{Referências}

Aulagnier, P. (1975). A Violência da Interpretação: Do Pictograma ao Enunciado (M. C. Pelegrino, Trans.). Rio de Janeiro: Imago.

Azevedo, L. J. d., Féres-Carneiro, T., \& Brandão, E. P. (2018). A transmissão na constituição do sujeito: uma abordagem lacaniana. Interação em Psicologia, 22 (2), (pp. 97-104). Doi: 10.5380/psi.v22i 2.49797 
Brasil. Ministério da Saúde. Protocolo de atenção à saúde e resposta à ocorrência de microcefalia / Plano nacional de enfrentamento à microcefalia - versão 3. Brasília, DF: Ministério da Saúde, 2016.

Brasil. Ministério da Saúde. (2017a) Ministério da Saúde declara fim da emergência nacional para zika. Recuperado em 3 jun. 2017 do Portal Governo do Brasil (http://www.brasil.gov.br/saude/2017/05/ministerio-da-saude-declara-fim-da-emergencia-nacionalpara-zika

Brasil. Ministério da Saúde. (2017b) Boletim Epidemiológico $n^{\circ} 17$. Volume 48 - 2017, Recuperado em 1 jun. 2017 da Secretaria de Vigilância em Saúde. ISSN 2358-9450 (http://portalarquivos.saude.gov.br/images/pdf/2017/junho/01/BE-2017-015-Monitoramentointegrado-de-alteracoes-no-crescimento-e-desenvolvimento.pdf)

Brasil. Ministério da Saúde. (2017b) Boletim Epidemiológico $n^{\circ} 31$. Volume 48 - 2017, Recuperado em 1 jun. 2017 da Secretaria de Vigilância em Saúde. ISSN 2358-9450 (http://portalarquivos2.saude.gov.br/images/pdf/2017/outubro/18/BE-Vol-48-n-31-2017-

Monitoramento-dos-casos-de-dengue-febre-de-chikungunya-ate-a-Semana-Epidemiologica-37.pdf)

CBPD. (2017). Congresso de Psicologia do Desenvolvimento: Pequisa e Intervenção para Promoção de Saúde ao longo do Ciclo Vital. Recuperado jan. 2018 da ABPD (http://www.cbpd2017.com.br/apresentacao)

Costa, A. (2016). Pesquisadora é eleita uma das 10 personalidades do ano na ciência. Agência Fiocruz de Notícias. Recuperado jun. 2017 do Portal Fiocruz (https://portal.fiocruz.br/pt-br/content/fiocruzpe-pesquisadora-e-eleita-uma-das-10-personalidades-do-ano-na-ciencia)

Crespin, G. (2004). A clínica precoce: o nascimento do humano. São Paulo: Casa do Psicólogo.

Dolto, F. (2013). Seminário de Psicanálise de Crianças (Márcia V. M. de Aguiar, Trad.). São Paulo: WMF Martins Fontes.(Trabalho original publicado em 1982)

Faria, M. R. (2016). Introdução à psicanálise de crianças: o lugar dos pais. São Paulo: Toro Editora.

Freud, S. (1996). Análise de uma fobia em um menino de cinco anos. In S. Freud, Edição standard brasileira das obras psicológicas de Sigmund Freud (J. Salomão, trad., Vol. 10, pp. 15-131). Rio de Janeiro: Imago. (Trabalho original publicado em 1909)

Freud, S. (1996). Sobre o narcisismo: uma introdução. In S. Freud, Edição Standard Brasileira das obras psicológicas de Sigmund Freud (J. Salomão, trad., Vol. 14, pp. 77-108). Rio de Janeiro: Imago. (Trabalho original publicado em 1914)

Freud, S. (1996) Conferências introdutórias à psicanálise. In S. Freud, Edição Standard Brasileira das obras psicológicas de Sigmund Freud (J. Salomão, trad., Vol. 15, pp. 25-33). Rio de Janeiro: Imago. (Trabalho original publicado em 1916)

Fulgencio, L. (2016). Os narcisismos e a sexualidade: da experiência narcísica de ser à experiência de investir libidinalmente o eu e os objetos. In J. Birman, L. Fulgencio, D. Kupermann \& E. L. Cunha (Eds.), Amar a si mesmo e amar o outro. Narcisismo e sexualidade na psicanálise contemporânea (pp. 215-224). São Paulo: Zagodoni.

Houzel, D. (2004). As implicações da parentalidade. In: Solis-Ponton, L. (Org.). Ser pai, ser mãe. Parentalidade: um desafio para o terceiro milênio. (pp. 48-51) São Paulo: Casa do Psicólogo.

Iaconelli, V. (2015). Mal-estar na maternidade: Do infanticídio à função materna. São Paulo: AnnaBlume Editora.

Lacan, J. (1998). A instância da letra no inconsciente ou a razão desde Freud. In J. Lacan, Escritos (I. Oseki-Depré, trad., pp. 223-260). São Paulo: Perspectiva. (Trabalho original publicado em 1957)

Lacan, J. (1998). O estádio do espelho como formador da função do eu. In J. Lacan, Escritos (V. Ribeiro, trad., pp. 96-103). Rio de Janeiro: Jorge Zahar Editor. (Trabalho original publicado em 1949) 
Laplanche, J. \& Pontalis, J.-B. (1986). Vocabulário da psicanálise. (P. Tamen, trad., pp. 212-213). São Paulo: Martins Fontes.

Laznik, M.-C. (2004). A voz da sereia: o autismo e os impasses na constituição do sujeito (C. F. Rohenkol et al, Trad., $2^{a}$ ed.). Salvador: Álgama.

Nunes, J., \& Pimenta, D. N. (2016). A epidemia de zika e os limites da saúde global. Lua

Nova: revista de cultura e política, (98), (pp. 21-46). doi:10.1590/0102-6445021-046/98

Puff, J. (2017). Zika e Olimpíada: Duas visões científicas sobre riscos a atletas e turistas. Recuperado 3 jun. 2017 do Portal BBC Brasil. (http://www.bbc.com/portuguese/brasil-36504916)

Roudinesco, E. \& Plon, M. (1998). Dicionário de psicanálise. (V. Ribeiro e L. Magalhães, trad., pp. 243-244). Rio de Janeiro: Jorge Zahar Editor.

Vander Linden, V., Pessoa, A., Dobyns, W., Barkovich, A. J., Júnior, H. Vander L., Filho, E. L. R., Moore, C. A. (2016). Description of 13 Infants Born During October 2015-January 2016 With Congenital Zika Virus Infection Without Microcephaly at Birth - Brazil. MMWR. Morbidity and Mortality Weekly Report, 65(47), (pp. 1343-1348). doi:10.15585/mmwr.mm6547e2

Ventura, C. V., Maia, M., Dias, N., Ventura, L. O., \& Belfort, R. (2016). Zika: neurological and ocular findings in infant without microcephaly. The Lancet, 387(10037), (p. 2502). doi:10.1016/s01406736(16)30776-0

Viodé-Bénony, C. G., Bernard. (2012). Psychopatologie du bébé. Paris: Armand Colin.

Winnicott, D. W. (2000). A Preocupação Materna Primária. In D. W. Winnicott, Da Pediatria à Psicanálise: Obras Escolhidas (D. Bogomoletz, trad., pp. 399-405). Rio de Janeiro: Imago Ed. (Trabalho original publicado em 1958)

Winnicott, D. W. (1983). Distorção do Ego em Termos de Falso e Verdadeiro Self. In D. W. Winnicott, O Ambiente e os Processos de Maturação (I. C. S. Ortiz, trad., pp. 128-139). Porto Alegre: Artmed. (Trabalho original publicado em 1960)

Winnicott, D. W. (1975). O Papel de Espelho da Mãe e da Família no Desenvolvimento Infantil In D. W. Winnicott, $O$ Brincar \& a Realidade (J. O. De A. Abreu e V. Algamis, trad., pp. 153-162). Rio de Janeiro: Imago Ed. (Trabalho original publicado em 1967)

Zornig, S. M. A.-J. (2010). Tornar-se pai, tornar-se mãe: o processo de construção da parentalidade. Tempo psicanalítico, v.42.2, (pp. 453-470).

Zorzetto, R. (2016). Incertezas sobre a microcefalia. Pesquisa Fapesp, ed. 241 (pp. 14-21) - 03/2016. Recuperado em jun. 2017 no portal da revista Fapesp (http://revistapesquisa.fapesp.br/2016/03/18/incertezas-sobre-a-microcefalia/)

Recebido em fevereiro/2018 - Aceito em abril/2019. 